\title{
Hypolipidaemic effect of ethanol leaf extract of Moringa oleifera Lam. in experimentally induced hypercholesterolemic wistar rats
}

\author{
Denen Atsukwei ${ }^{1}$, Ejike Daniel Eze ${ }^{1, ~}$, , Moses Dele Adams ${ }^{2}$, Seriki Samuel Adinoyi ${ }^{1}$, \\ Chiamaka Nnenna Ukpabi ${ }^{1}$ \\ ${ }^{1}$ Department of Physiology, Faculty of Basic Medical Sciences, Bingham University, Karu, Nasarawa State, Nigeria \\ ${ }^{2}$ Department of Biochemistry, Faculty of Science and Technology, Bingham University, Karu, Nasarawa State, Nigeria
}

\section{Email address:}

daneze4@gmail.com (E. D. Eze)

\section{To cite this article:}

Denen Atsukwei, Ejike Daniel Eze, Moses Dele Adams, Seriki Samuel Adinoyi, Chiamaka Nnenna Ukpabi. Hypolipidaemic Effect of Ethanol Leaf Extract of Moringa Oleifera Lam. in Experimentally induced Hypercholesterolemic Wistar Rats. International Journal of Nutrition and Food Sciences. Vol. 3, No. 4, 2014, pp. 355-360. doi: 10.11648/j.ijnfs.20140304.28

\begin{abstract}
The hypolipidaemic effect of ethanol leaf extract of Moringa oleifera in experimentally induced hypercholesterolemic rats was investigated. Thirty six (36) wistar rats of both sexes weighing $130.53 \pm 4.86$ were used for the study. The animals were completely randomized into six groups (A-F) comprising 6 animals each. Groups A, B and C comprise female rats administered $1 \mathrm{ml}$ of distilled water, high dose of $600 \mathrm{mg} / \mathrm{kg}$ and low dose of $300 \mathrm{mg} / \mathrm{kg}$ body weight of the extract respectively. Groups D, E and F comprise male rats administered $1 \mathrm{ml}$ of distilled water, high dose of 600 $\mathrm{mg} / \mathrm{kg}$ and low dose of $300 \mathrm{mg} / \mathrm{kg}$ body weight of the extract respectively. Hypercholesterolemia was induced by feeding the animals with high fat diet for 21 days before administration of the extract. After the 21 days of feeding, administration of extract lasted for 14 days. Preliminary phytochemical screening revealed that the ethanol leaf extract of $M$. oleifera contains alkaloids, tannins, carbohydrates and cardiac glycosides. Only the high dose female group $(600 \mathrm{mg} / \mathrm{kg}$ body weight) lost or maintained their body weight significantly $(\mathrm{p}<0.05)$, the rest did not. Body weight was not significantly $(p>0.05)$ altered in the male group administered low dose and high dose, showing that the dose of the extract slightly affected their weight. For serum lipids, serum total cholesterol concentration in both male and female reduced significantly $(\mathrm{p}<0.05)$, both in those given low and high doses of the extract. Serum high density lipoprotein cholesterol (HDLC) level significantly $(\mathrm{p}<0.05)$ increased both in male and female rats that were administered high dose of $600 \mathrm{mg} / \mathrm{kg}$ body weight of the extract, but was not significantly ( $p>0.05$ ) affected in other groups. Serum low density lipoprotein cholesterol (LDLC) level also reduced significantly $(\mathrm{p}<0.05)$ in both male and female rats that were administered high dose of the extract, but was not significantly ( $>0.05)$ altered for those that received low doses $(300 \mathrm{mg} / \mathrm{kg}$ body weight) of the extract. There was no significant $(p>0.05)$ reduction in the LDLC of the male rats. Serum triacylglycerol (TAG) concentration in male and female rats reduced significantly $(\mathrm{p}<0.05)$, in those that received low and high doses of the extract. Overall, findings from the present study suggest that the ethanol leaf extract of $M$. oleifera has hypolipidaemic effect. Therefore, the leafy vegetable may be recommended to patients that have problems with high serum lipid profiles and also for people that want to lose or maintain body weight.
\end{abstract}

Keywords: Moringa Oleifera, Body Weight, High Fat Diet, Hypercholesterolemia, Serum Lipid, Hypolipidaemic Effect

\section{Introduction}

Moringa oleifera Lam. is the most widely cultivated species of the monogeneric family Moringaceae, which includes 13 species of trees and shrubs distributed in sub-
Himalayan ranges of India, Sri Lanka, North-eastern and South-western Africa, Madagascar and Arabia [11]. Moringa is also native to parts of West Africa particularly Nigeria [29]. It is commonly known in Hausa (Northern Nigeria) as Zogale. English common names include moringa and drumstick tree [36]. M. oleifera is one of the 
most useful tropical trees [12]. The Moringa tree is a multifunction plant. It has been cultivated in tropical regions all over the world for the following characteristics: high protein, vitamins, mineral and carbohydrate content of entire plants; high value of nutrition for both humans and livestock; high oil content (42\%) of the seed which is edible, and with medicinal uses; the coagulant of seeds could be used for wastewater treatment [8]. Previous studies by Amaglo et al. [3], Limon-Pacheco and Gonsebatt [19], and Mahajan and Mehta [20] have reported the pharmacological, antioxidant, and anti-inflammatory property of $M$. oleifera respectively. Furthermore, Awodele et al., [4] worked on the toxicological evaluation of the aqueous extract of Moringa oleifera Lam (Moringaceae). Oyedepo et al., [26] evaluated the anti-hyperlipidemic effect of aqueous leaves extract of Moringa oleifera while Gupta et al., [15] worked on the evaluation of antidiabetic and antioxidant activity of Moringa oleifera in experimental diabetes. Again, Jaiswal et al [17] worked on the role of Moringa oleifera in regulation of diabetesinduced oxidative stress while Choudhary et al., [7] assessed the antiulcer potential of Moringa oleifera root bark extract in rats. Although there have been several reports on the cholesterol reducing effect of the aqueous and ethanol leaf extracts of $M$. oleifera in rats, there is still paucity of information on the hypolipidaemic activity of the extract at the doses investigated in the present study. Again, considering the use of $M$. oleifera for the treatment of various ailments, there is the need to investigate the possible effect of the plant on some biochemical parameters as it relates to weight and lipid in animals. In this study, we therefore present information on the hypolipidaemic effect of ethanol leaf extract of Moringa oleifera on the body weight and serum lipid profile using experimentally induced hypercholesterolemic wistar rats as model.

\section{Materials and Methodology}

\subsection{Materials}

\subsubsection{Plant Materials and Authentication}

Fresh leaves of Moringa oleifera was procured at Mrs. Bali's home farm at No. 10 Kuchikau Road, Auta Balefi, Karu LGA, Nasarawa State, Nigeria, and was authenticated by the Botany Department of Federal University of Technology, Yola with voucher specimen number: BC/FUTY/DD02/2004.

\subsubsection{Experimental Animals}

Wistar rats (Rattus norvegicus) of both sexes weighing $130.53 \pm 4.86 \mathrm{~g}$ were obtained from the Animal House of Federal College of Animal Health and Production Technology (FCAH \& PT), VOM, Jos, Plateau State, Nigeria.

\subsubsection{Assay Kits}

The assay kits for the determination of serum total cholesterol, high-density lipoprotein cholesterol (HDLC), low-density lipoprotein cholesterol (LDLC) and triacylglycerol (TAG) were products of Randox Laboratory Ltd, Co-Atrium, United Kingdom.

\subsubsection{Other Reagents}

All other chemicals and reagents used which were of analytical grade were products of sigma Aldrich Ltd., Buchs, Canada and are prepared in volumetric flask using glass wares with distilled water except otherwise stated.

\subsection{Methodology}

\subsubsection{Formulation of High Fat Diet}

The high fat diet was prepared by adopting the procedure described by [25] with little modification. Briefly, composition of the experimental diet include: $50.0 \%$ (Cholesterol rich butter + hydrogenated sunflower oil), 25.0\% Garri, 20.0\% (Bonga fish + egg yolk), 1.5\% Fiber, $2.5 \%$ Mineral mixture and $1.0 \%$ Vitamin mixture making up $100 \%$, which gives an energy requirement of 6.35 $\mathrm{KCal} / \mathrm{g}$. This was done by mixing these components in an experimental bowl. After preparation, it was dried at room temperature, and then administered to the animals to induce hypercholesterolemia.

\subsubsection{Preparation of Ethanolic Leaf Extract of Moringa Oleifera}

Fresh leaves of Moringa oleifera were air dried under a shade until a constant weight was obtained. This was thereafter pulverized in a blender (PHILIPS, Model HR1724, Brazil). A known weight (250 g) of the powder was extracted in $1000 \mathrm{ml}$ of $70 \%$ ethanol for 72 hours at room temperature. The extract was filtered with Whatman No. 1 filter paper (Maidstone, UK) and the resulting filtrate concentrated in a Rotary Evaporator, where some ethanol was recovered. The mixture was further transferred into steam bath where it was evaporated to give the required brownish-black residue. This was then reconstituted in distilled water to give the required low and high doses (300 and $600 \mathrm{mg} / \mathrm{kg}$ body weight) used in the present study.

\subsubsection{Phytochemical Screening}

Preliminary phytochemical screening to detect the presence of alkaloids, saponins, tannins, carbohydrates were carried out by adopting the methods described by Harborne [16], Walls et al., [37], Odebiyi and Sofowora [24], Trease and Evans [34] respectively. Steroids, anthraquinones and cardiac glycosides were carried out by adopting the procedures described by El-Olemy et al., [8], Mainasara et al., [21] and Sofowora [32] respectively.

\subsubsection{Determination of Body Weight}

The weight of individual rat of each group was measured 'only' before and after administration of extract.

\subsubsection{Animal Grouping, Feeding and Extract Administration}

A total of thirty six (36) wistar rats, housed in clean aluminum cages contained in well ventilated standard 
housing conditions (temperature: $28-31^{\circ} \mathrm{C}$; photoperiod: 12 hours; humidity: $50-55 \%$ ) was used for the study. The animals were allowed free access to rat pellets (Premier Feed Mill Co. Ltd., Ibadan, Nigeria) and tap water ad libitum. The cages were also cleaned on daily basis. The animals were acclimatized for two weeks before the commencement of the experiment. The animals were completely randomized into six groups (A-F) comprising 6 animals each. Groups A, B and C comprise female rats administered $1 \mathrm{ml}$ of distilled water, high dose of 600 $\mathrm{mg} / \mathrm{kg}$ and low dose of $300 \mathrm{mg} / \mathrm{kg}$ body weight of the extract respectively. Groups D, E and F comprise male rats administered $1 \mathrm{ml}$ of distilled water, high dose of 600 and low dose of $300 \mathrm{mg} / \mathrm{kg}$ body weight of the extract respectively. Hypercholesterolemia was induced by feeding the animals with high fat diet for 21 days before administration of any extract. After the 21 days of feeding, administration of extract lasted for 14 days using metal oropharyngeal cannula. The animals were handled humanely according to the guidelines of European convention for the protection of vertebrate animals and other scientific purposes- ETS-123 [10].

\subsubsection{Collection of Serum}

The rats were anaethesized in a glass jar containing cotton wool soaked in diethyl ether. The unconscious rats were quickly removed and the neck area cleared of fur. The jugular vein which was slightly displaced (to avoid contamination of the blood with interstitial fluid) was cut with a sterile scapel blade and an aliquot of the blood was collected into a sample bottle. The blood was then left undisturbed for 10 minutes at room temperature to clot. The blood was thereafter centrifuged at $224 \mathrm{x}$ g for 10 minutes using Uniscope Laboratory Centrifuge (Model 800D, New Life Medical Instrument, England). The sera were later aspirated with Pasteur pipette into dry, sample bottles and used within 12 hours of preparation for the determination of serum lipid profile.

\subsubsection{Statistical Analysis}

Results were expressed as the mean \pm SEM of six determinations. The data were analyzed using Duncan Multiple Range Test and complemented with Student's ttest. The differences were considered statistically significant at $\mathrm{p}<0.05$. All these analyses were done using SPSS 20.0 Software (Statistical Package for Social Sciences, Inc., Chicago, IL, USA).

\section{Results}

Preliminary phytochemical screening of the ethanol leaf extract of Moringa oleifera revealed the presence of alkaloids, tannins, carbohydrates and cardiac glycosides while saponins, steroids and anthraquinones were not detected (Table 1).

Only the high dose $(600 \mathrm{mg} / \mathrm{kg}$ body weight) female group lost or maintained their body weight significantly $(p<0.05)$, the rest did not. However, body weight was not significantly $(\mathrm{p}>0.05)$ different in the male group administered low and high doses, showing that these doses of the extract did not produce any change on their body weight (Figure 1).

The study revealed that serum total cholesterol levels in both male and female reduced significantly $(p<0.05)$, both in those that received low $(300 \mathrm{mg} / \mathrm{kg}$ body weight) and high $(600 \mathrm{mg} / \mathrm{kg}$ body weight) doses of the extract (Figure 2).

Serum high density lipoprotein cholesterol (HDLC) level significantly $(p<0.05)$ increased both in male and female rats that were administered high dose $(600 \mathrm{mg} / \mathrm{kg}$ body weight) of the extract, but was not significantly $(p>0.05)$ affected in other groups (Figure 3).

Serum low density lipoprotein cholesterol (LDLC) also reduced significantly $(\mathrm{p}<0.05)$ in both male and female rats that were administered high dose $(600 \mathrm{mg} / \mathrm{kg}$ body weight $)$ of the extract, but was not significantly $(\mathrm{p}>0.05)$ altered in those that received low doses $(300 \mathrm{mg} / \mathrm{kg}$ body weight $)$ of the extract. There was no significant $(\mathrm{p}>0.05)$ reduction in the LDLC of the male rats (Figure 4).

Serum triacylglycerol (TAG) levels in both male and female rats decreased significantly $(\mathrm{p}<0.05)$, in those that received low and high doses ( 300 and $600 \mathrm{mg} / \mathrm{kg}$ body weight respectively) of the extract (Figure 5).

Table 1. Phytochemical constituents of ethanol leaf extract of Moringa oleifera

\begin{tabular}{ll}
\hline Constituents & Result \\
\hline Alkaloids & +++ \\
Saponins & - \\
Tannins & +++ \\
Carbohydrates & ++ \\
Steroids & - \\
Anthraquinones & - \\
Cardiac glycosides & ++ \\
\hline
\end{tabular}

Key: $(+)=$ Present $(-)=$ Absent

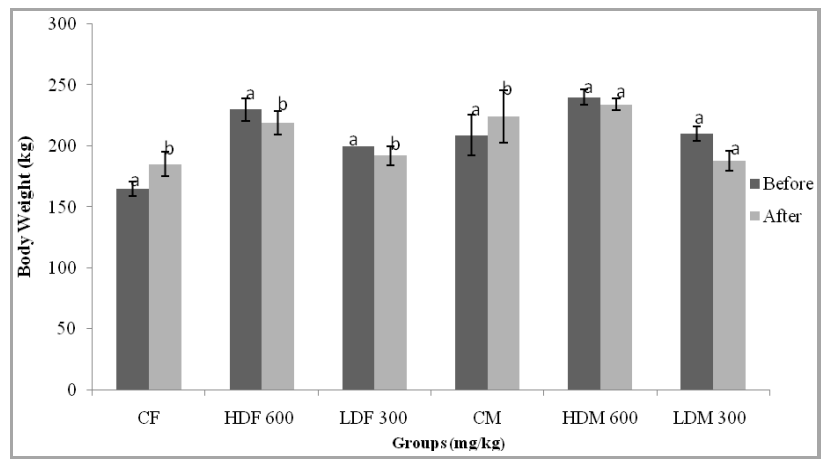

Figure 1. Effect of administration of ethanol leaf extract of Moringa oleifera on body weight of rats

Key: $\mathrm{CF}=$ Control Female, HDF $=$ High Diet Female, $\mathrm{LDF}=$ Low Diet Female, $\mathrm{CM}=$ Control Male, HDM= High Diet Male, LFM= Low Diet Male 


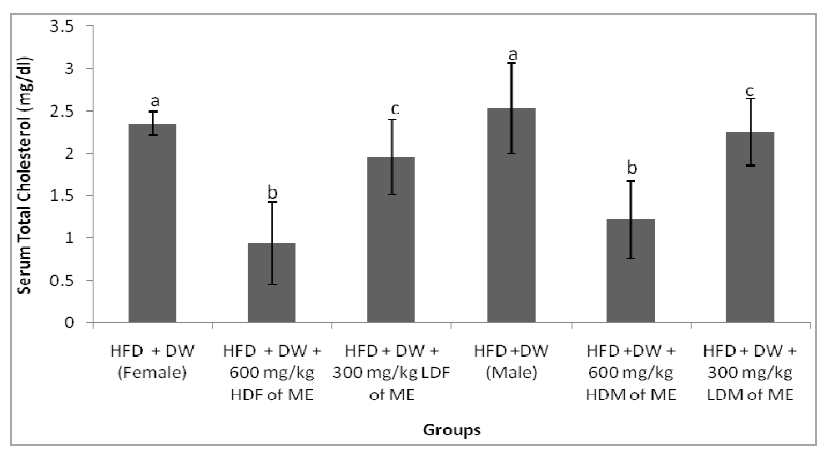

Figure 2. Effect of administration of ethanol leaf extract of Moringa oleifera on serum total cholesterol of rats

Key: HFD = High Fat Diet, DW= Distilled Water, ME= Moringa Extract, HDF $=$ High Dose Female, LDF $=$ Low Dose Female, HDM= High Dose Male, $\mathrm{LDM}=$ Low Dose Male

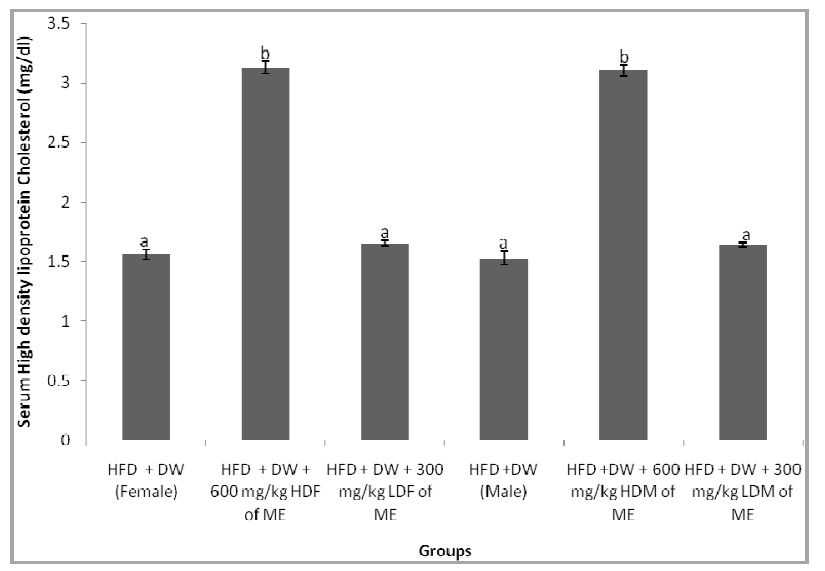

Figure 3. Effect of administration of ethanol leaf extract of Moringa oleifera on serum high density lipoprotein cholesterol (HDLC) of rats

Key: HFD = High Fat Diet, DW= Distilled Water, ME= Moringa Extract, HDF $=$ High Dose Female, LDF= Low Dose Female, HDM= High Dose Male, $\mathrm{LDM}=$ Low Dose Male

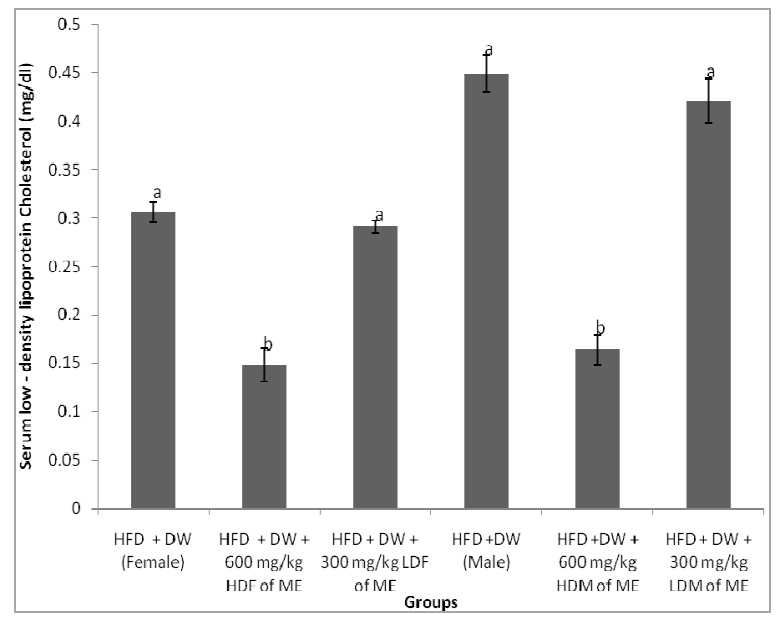

Figure 4. Effect of administration of ethanol leaf extract of Moringa oleifera on serum low density lipoprotein cholesterol (LDLC) of rats

Key: HFD= High Fat Diet, DW= Distilled Water, ME= Moringa Extract, HDF $=$ High Dose Female, LDF= Low Dose Female, HDM= High Dose Male, $\mathrm{LDM}=$ Low Dose Male

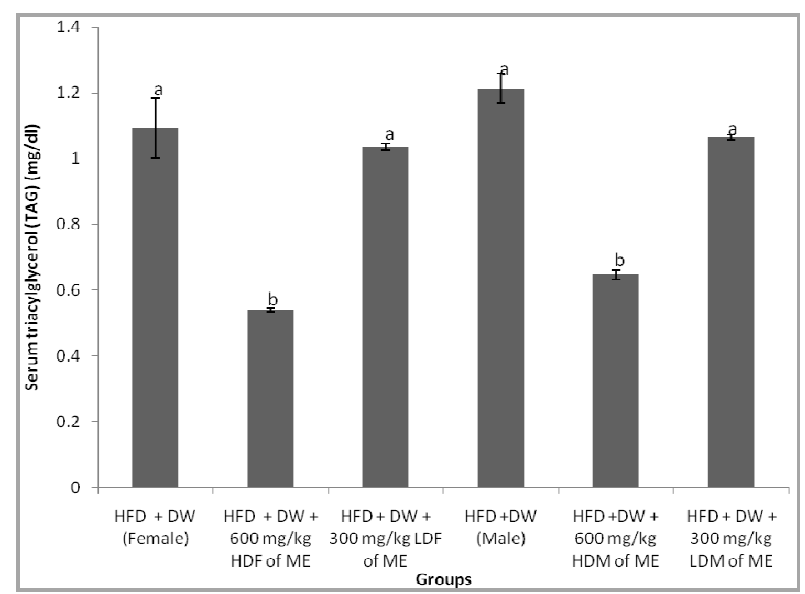

Figure 5. Effect of administration of ethanol leaf extract of Moringa oleifera on serum triacylglycerol (TAG) of rats

Key: DW= HFD $=$ High Fat Diet, Distilled Water, ME= Moringa Extract, HDF $=$ High Dose Female, LDF= Low Dose Female, HDM= High Dose Male, $\mathrm{LDM}=$ Low Dose Male

\section{Discussion}

The incidence of obesity, which results from intake of high fat diet and other metabolic disorders, is rising at an alarming rate and is becoming a major public health concern with incalculable social cost. Indeed, obesity facilitates the development of metabolic disorders such as diabetes, hypertension, and cardiovascular diseases such as stroke, osteoarthritis, apnea, some cancers and inflammation-bases pathology [14]. Alterations in the concentration of major lipids like serum total cholesterol, high-density lipoprotein cholesterol (HDLC), low-density lipoprotein cholesterol (LDLC) and triacylglycerol (TAG) could give useful information on the lipid metabolism as well as predisposition of the heart to atherosclerosis and its associated coronary heart diseases [38].

The hypolipidaemic activity of several medicinal plants has been associated to bioactive agents like alkaloids, tannins, and cardiac glycosides. Alkaloids may mediate hypolipidaemic action either by up regulation of activities of lipolytic enzymes or by stimulating faecal file acid excretion in agreement with previous findings by Mathur $e t$ al., [22]. Also, other phytoconstituents and $\beta$-sitosterol present in the extract could be the major cholesterolreducing components of the ethanol leaf extract of $M$. oleifera as it may work singly or in synergy with other bioactive agents [33].

The significant reduction in body weight by the extract in female rats fed with high fat diet may be partly attributed to inhibition of cholesterol deposition in body tissues or inhibition of HMG CoA reductase activity which is the key regulatory enzyme in cholesterol biosynthetic pathway $[1,2$, 27]. This implies that the extract may be recommended for persons who want to lose weight. For the male rats, since the extract at both doses did not significantly affect the body weight when compared with the control animals, it "may" also be recommended in maintaining body weight. 
The phytochemical constituents and $\beta$-sitosterol present are the major cholesterol-reducing components of the Moringa oleifera leaf. $\beta$-sitosterol helps in reducing cholesterol levels by limiting the amount of cholesterol that is able to enter the body, by inhibiting cholesterol absorption in the intestines $[5,13]$. The structure of $\beta$-sitosterol is similar to that of cholesterol. $\beta$-sitosterol takes the place of dietary and biliary cholesterol in micelles produced in the intestinal lumen and this reduces cholesterol absorption in the body. Therefore, instead of cholesterol being absorbed, the $\beta$-sitosterol in moringa oleifera will be absorbed. Another way cholesterol can be reduced is by reduction in LDLC. LDLC carries cholesterol from the liver to the blood stream. Therefore, when LDLC is reduced, the amount of cholesterol being carried will also reduce [30]. Chlorogenic acid and moriginine are also constituents of Moringa oleifera and they reduce serum total cholesterol [6]. Similarly, the decrease in serum total cholesterol observed with the extract at 600 $\mathrm{mg} / \mathrm{kg}$ body weight (female) may be due to decrease in the concentration of acetyl CoA arising probably from reduced $\beta$-oxidation of fatty acid, since acetyl-CoA is a key substrate in the biosynthesis of cholesterol [31]. Low blood cholesterol concentration is one of the important beneficial factors that do not predispose an individual to cardiovascular diseases [35]. Therefore, such decrease in the serum lipid contents may be beneficial to the animals as it may not enhance obesity, atherosclerosis and hypertension [9].

High density lipoprotein cholesterol (HDLC) is considered to have anti-atherogenic properties. It has also been shown that increase in HDLC correlates inversely with coronary heart disease [23]. In the present study, administration of $600 \mathrm{mg} / \mathrm{kg}$ body weight of the extract to both female and male animals, which showed significant increase in serum HDLC when compared to the control animals is beneficial, and 'may' not predispose the animals to cardiovascular risk.

For low density lipoprotein cholesterol (LDLC), it is known that for being effective antihyperlipidemic agent, the compound should reduce the plasma levels of LDLC, as it transports $70 \%$ of plasma cholesterol in humans [28]. Epidemiological and clinical studies have demonstrated positive correlation in LDLC concentration in serum and risk of coronary heart diseases [5]. This result showed significant decrease in serum LDLC level as a function of treatment with the ethanol leaf extract of $M$. oleifera. Part of the insignificance can be attributed to lower concentration of bioactive phytochemicals involved in inhibition of the uptake of dietary and biliary cholesterol, thereby reducing LDLC levels.

Triacylglycerols are the main storage form of fatty acids. The decrease in serum triacylglycerol by the ethanol leaf extract of $M$. oleifera may be due to reduced lipolysis. This may deplete the store of fatty acids. Also, the reduced serum triacylglycerol (TAG) level in the treated animals could be co-related to elevated lipoprotein lipase activity which is in agreement with previous studies by Phil-Sun et al [28] and Kannel et al [18] on mushroom extracted exo- biopolymer. Overall, the study showed that there was reduced level of all lipids except the HDL-C, and this may be beneficial to the animal as this pattern of alterations are associated with reduced risk of atherosclerosis and its coronary heart diseases.

\section{Conclusion}

The result of the present study has shown that ethanol leaf extract of Moringa oleifera has hypolipidaemic effect mainly in terms of reduction in serum lipids and body weight loss. Cholesterol-reducing action of the extract indicates that this leafy vegetable possess medicinal value which could validate and explain its ethno-medical use on obese persons as well as other related cardiovascular diseases. Therefore, ethanol leaf extract of M. oleifera may be recommended to patients having problems with high serum lipid profiles, and also for people that want to lose or maintain body weight.

\section{References}

[1] Alberts AW, Chen J, Curon G, Hunt V, Huff J, Hoffman C, Rothrock J, Lopez M, Oshau H, Harris E, Patchett A, Monaghan R, Currie S, Stapley E, Albers-Schonberg G, Hensen O, Hirschfield J, Hoogsteen K, Liesch J, Springer J, and Mevinonlin P. A highly potent competitive inhibitor of hydroxyl methyl glutaryl coenzyme A reductase and cholesterol-lowering agent. Proc Natl Acad Sci., 1980; 77:3957.

[2] Altschul R. Influence of nicotinic acid (Niacin) on hypercholesterolemia and hyperlipedemia and on the course of atherosclerosis. In: Altschul R, editor. Niacin in vascular disorder of and hyperlipidemia Springfield, IL: Charles C. Thomas; 1964; Pp. 135.

[3] Amaglo NK, Bennett RN, Lo-Curto RB, Rosa EAS, LoTurco V, Giuffrid A, Lo Curto A.Crea F, and Timpo GM. Profiling selected phytochemicalsand nutrients in different tissues of the multipurpose tree Moringa oleifera L. grown in Ghana. Food Chem., 2010; 122, 1047-1054.

[4] Awodele O, Oreagba IA, Odoma S, Silva JAT, Osunkalu VO. Toxicological evaluation of the aqueous extract of Moringa oleifera Lam (Moringaceae). J Ethnopharmacol 2012, 139: 330-336.

[5] Bordia A, and Verma SK. Effect of Celastrus paniculatus wild oil (Bravobol) on blood lipids in patients of coronary. Antiseptic, 1998; 95(4)112.

[6] Cho AS, Jeon SM, Kim MJ. "Chlorogenic acid and moriginine exhibit anti-obesity property and improves lipid metabolism in high-fat diet-induced-obese mice". Food and Chemical Toxicology. 2010. Vol. 48, No. 3. Pp. 937-943.

[7] Choudhary MK, Bodakhe SK, Gupta SK. Assessment of the antiulcer potential of Moringa oleifera root bark extract in rats. J Acupunct Meridian Stud (2013).

[8] El-Olemy MM, Al-Muhtadi FJ, Afifi AA. Experimental Phytochemistry. A laboratory Manual. Riyadh, Saudi Arabia: King Saud University Press, 1994. 
[9] Enas EA. Cholesterol made easy: The good, bad and the ugly. (CADI Research, USA) 1999; 1.

[10] European Treaty Series, 2005. European Convention for the protection of vertebrate animals used for experimental and other scientific purposes. European Treaty Series, Strasbourg, ETS-123.

[11] Fahey JW. A Review of the Medical Evidence for Its Nutritional, Therapeutic, and Prophylactic Properties. Part1. Trees Life Journal, 2005;1: 5-15.

[12] Foidl N, Makkar HPS, and Becker K. The potential of Moringa oleifera for agricultural and industrial uses. In: "The Miracle Tree/ The Multiple Attributes of Moringa" (Ed. Lowell J Fuglie). CTA. USA, 2001.

[13] Frawley BA. _Phytochemicals in plant-based foods could help battle obesity, diseases. Health Research, 2009; afrawley@ufl.edu 352-273-5817.

[14] Gonzalez-Castejon M, and Rodriguez-Casado A. Dietary phytochemicals their potential effects on obesity: a review. Pharmacol Res. 2001; Nov ;64(5):438-55.PMID 21798349.

[15] Gupta et al. Evaluation of antidiabeticand antioxidant activity of Moringa oleifera in experimental diabetes. $J$ Diabetes (2012).

[16] Harborne J D. Phytochemical methods: A guide to modern techniques of plant analysis. Chapman \& Hall, London, 1973. p. 279.

[17] Jaiswal D. et al. Role of Moringa oleifera in regulation of diabetes-induced oxidative stress. Asian Pac J Trop. Med. 2013.

[18] Kannel WB, Castelli CW, Gordon T, and McNamara PM. Serum cholesterol, lipoprotein, and the risk of coronary heart diseases. Ann Intern Med., 1971;74:1.

[19] Limon-Pacheco J, and Gonsebatt ME. The role of antioxidants and antioxidant-related enzymes in protective responses to environmentally induced oxidative stress. Mutat. Res., 2009; 674, 137-147.

[20] Mahajan S, and Mehta A. Curative effect of hydroalcoholic extract of leaves of Moringa oleifera lam. against adjuvant induced established arthritis in rats. Niger. J. Nat. Prod. Med., 2009; 13, 13-22.

[21] Mainasara MM, Aliero BL, Aliero AA, Yakubu M. Phytochemical and antibacterial properties of root and leaf extract of Calotropis procera. Nig. J. Basic Appl. Sci. 2012, 20(1):1-6.

[22] Mathur NT, Varma M, and Dixit VP. Hypolipidemic and antiatherosclerotic effect of Celastrus paniculatus seed extract $(50 \% \mathrm{E}-\mathrm{OH})$ in cholesterol fed rabbits. Indian Drugs, $1993 ; 30(2) 76$.

[23] Mayes PA. Lipid transport and storage, in Harper's biochemistry, edited by Murray R K, Granner D K, Mayes P A \& Rodwell V W, 24th edition (Prentice Hall International, Inc., USA) 1996, 254.

[24] Odebiyi A. and Sofowora AE. Phytochemical screening of Nigerian medicinal plant. Part III, Lloydia, 1978. 41, 234246.
[25] Onyeneke EC. and Anyanwu GO. Effect of Alstonia boonia De Wild on high fat diet induced obesity in male wistar rats. European Journal of Scientific Research., 2013; Vol 112, No 3. Pp 292-299.

[26] Oyedepo TA, Babarinde SO, Ajayeoba TA. Evaluation of Anti-hyperlipidemic Effect of Aqueous Leaves Extract of Moringa oleifera in Alloxan Induced Diabetic Rats. International Journal of Biochemistry Research \& Review 3(3): 162-170.

[27] Patil RH, Prakash K, and Maheshwari VL. Hypolipidemic effect of Celastrus paniculatus in experimentally induced hypercholesterolemic Wistar rats. Indian J Clin Biochem., 2010; 25(4):405-410.

[28] Phil-Sun O, Sei-Jung L, and Kye-Taek L. Hypolipidemic and antiobedetive of the plant glycoprotein $(36 \mathrm{KDa})$ from the Rhus vernicufulia stokes fruit in Triton WR-1339 induced hyperlipidemic rats. Biosci Biotechnol Biochem. 2006; 70(2):447.

[29] Quattrocchi NT, and Umberto MP. CRC World Dictionary of Plant Names: Common Names, Scientific Names, Eponyms, Synonyms, and Etymology. 2000; Volume 3: MQ. CRC Press. p. 1731. ISBN 978-0-8493-2677-6. http://books.google.co.uk/books?id=kaN-hLL-3qEC\&dq

[30] Rana JS, Nieuwdorp M, Jukema JW, and Kastelein JJ. Cardiovascular metabolic syndrome-an interplay of, obesity, inflammation, diabetes and coronary heart disease. Diabetes Obes. Metab., 2007; 9:218-232.

[31] Rang AP, Dale MM, and Ritter JM. Pharmacology. 3rd edn (Churchill Livingstone, New York) 1995; 409.

[32] Sofowora A. Medicinal Plants and Traditional Medicine in Africa, 2nd Edition, Spectrum Books, Ibadan, Nigeria; 1993. 26-100.

[33] Tandon S. Phytochemicals and cardiovascular health. High Current R and D. 2005; 28:18-22.

[34] Trease G.E, and Evans MC. A textbook of Pharmacognosy, 1983. $12^{\text {th }}$ ed. Bailliere-Tindall Ltd., London. 1983. Pp. 343-383.

[35] Treasure CB, Klein JL, Weintraub WS, Talley JD, Stillabow ME, Kisonski AS, Zhang J, Boccuzzi SJ, Codarholm JC, and Alexander RW. Beneficial effects of cholesterol lowering therapy on the coronary endothelium in patients with coronary heart disease. New England Journal of Medicine, 1995; 332: 481.

[36] Verzosa BR, and Caryssa LH."Malunggay and Spinach Powder (Investigatory Project Sample)".Scribd.com.http://www.scribd.com/doc/29164852/ Malunggay-and-Spinach-Powder-Investigatory-ProjectSample;2012.

[37] Walls ME, Wani MC, Brown DM, and Fullas F. Effect of tannins on screening of plant extracts for enzyme inhibitory activity and techniques for their removal. Phytomedicine, $1996,3,281-285$.

[38] Yakubu M T, Akanji MA, and Oladiji AT. Alterations in serum lipid profile of male rats by oral administration of aqueous extract of Fadogia argrestis stem, Res J Med Plant 2,$2008 ; 66$. 